\title{
Effects of Consumer Preferences on Environmentally Friendly Tomatoes in Myanmar
}

\author{
Myo Sabai Aye ${ }^{1,2}$, Yoshifumi Takahashi ${ }^{1} \&$ Mitsuyasu Yabe ${ }^{1}$ \\ 1 Department of Agricultural Resource Economics, Graduate School of Bioresource and Bioenvironmental \\ Sciences, Faculty of Agriculture, Kyushu University, Fukuoka, Japan \\ ${ }^{2}$ Department of Agricultural Economics, Yezin Agriculutral University, Yezin, Naypyitaw, Myanmar \\ Correspondence: Mitsuyasu Yabe, Department of Agricultural Resource Economics, Faculty of Agriculture, \\ Kyushu University, Fukuoka, Japan. Tel: 81-092-802-4838. E-mail: yabe@agr.kyushu-u.ac.jp
}

Received: May 13, 2019

doi:10.5539/jas.v11n13p29
Accepted: June 25, $2019 \quad$ Online Published: August 15, 2019

URL: https://doi.org/10.5539/jas.v11n13p29

The research is financed by Japan International Cooperation Agency (JICA) for the master program for the Project on "Development of Core Human Resources in Agricultural Sector".

\begin{abstract}
Environmentally and economically sustainable agricultural production systems are crucial to conserve natural resources and the environment as well as to protect human health. In recent years, Myanmar, one of the agricultural-resource-rich developing countries, is confronting land degradation, environmental pollution, and food safety issues due to intensive agricultural methods that use high dosages of agro-chemical inputs. Myanmar environmental farming systems and the market for environmentally certified products are still under developed. Determining consumers' preferences and willingness to pay for environmentally certified products are vitally important to develop safe food markets. In this study, the choice experiment method was applied to examine consumer preference and the potential demand for environmentally friendly tomatoes. Using a sructured questionnaire in face to face interviews, the study collected information from 332 consumers in 8 supermarkets, and 4 open markets in Yangon city. Our results informed that most of the respondents in both markets have a positive WTP for an increase in each attribute. The supermarket respondents paid attentions to food safety labels, and it had the highest MWTP 2067.170 MMK (1.53 USD) relative to the other attributes. Our results suggest that policymakers and producers must enhance consumers' knowledge of what is an eco-product and how to differentiate it in the market place and emphasize the improvement of food safety certification programs.
\end{abstract}

Keywords: Choice experiment method, environmentally friendly tomato, consumers' preferences, willingness to pay

\section{Introduction}

\subsection{Background Information}

Increasing environmental pollution and chemical contamination of food pose a threat to the global environment. Pimentel et al. (1992) stated that high dosages of pesticides, especially in fruits and vegetables, pose a possibly severe health hazard to consumers by receiving contaminated drinking water and food crops. Fresh vegetables are an essential part of a healthy diet because they are an important source of vitamins and minerals; however, they, can also be a source of toxic pesticides (Kyaw, 2014). To control pests, farmers commonly use pesticides because they have an immediate effect, and they are readily available in the local market. Consequently, food poisoning cases have been on the rise due to chemical residues in food, especially in developing countries; this can be attributed to the fact that most farmers and marketers lack of knowledge how to control the contamination of chemical, physical, biological hazard, and weak of post-harvest activities. In recent years, consumers have expressed concern about environmental and health issues related to food products, such as foodborne illnesses. Thus, Myanmar's agriculture sector is attempting to turn around existing production systems to make them ecofriendly to maintain the natural environment and, human health as well as to earn more foreign exchange by exporting organic products to international market. In Myanmar, organic farming and Good Agricultural Practices (GAP) systems are applied for moving toward sustainable agricultural production. 


\subsection{Problem Statement and Objectives}

In Myanmar, tomato is an essential culinary crop among the vegetables and used in many ways in the daily diet. Tomato is an excellent source of many nutrients and secondary metabolites that are important for human health. However, most of the tomato growers use a high dosage of pesticides and chemical fertilizers; they heavily rely on these pesticides to protect the crops from pests and diseases. It is evident that production activities negatively impact the environmental quality, and hence it should be considered a crucial issue. In Myanmar, there is limited information on the response to safety vegetables of the demand side, what type of safety products want to buy and consume, which attributes are preferable when consumer purchases vegetables in the market and the reasonable price to charge for safety foods. And then, what is the key factors of influence for consumer preference for safety food. Currently, the full quality and safety foods marketing are still underdeveloped in Myanmar. Moreover, there is not too much research about the consumers' behavior and willingness to pay for environmentally friendly products of agricultural commodities in Myanmar. This research is the first approach to consumer survey about agricultural commodities by using environmentally friendly farming techniques.

The primary goal of this study is to investigate the marketability of environmentally friendly tomatoes in Myanmar and to provide information to policymakers and tomato producers about enhancing the quality, extending the market, and improving the profitability of these tomatoes. The specific objectives of this study are three-fold. First, the study aims to estimate the potential demand for environmentally friendly tomatoes in the local market. Second, the needed to enhance the safety of tomatoes during consumer purchase in different markets. Finally, the study aims to explore consumers' marginal willingness to pay (MWTP) for environmentally friendly tomatoes in different markets. This study assumes cconsumers who have higher income, smaller family size; younger age and knowledge about the environmentally sound techniques are expected to be more willing to pay for eco-friendly tomato. And then, the consumers could pay higher premium if organic or GAP certified labels are clearly provided with complete information for environmentally friendly tomato in the market. This research might assist to solve some of the currently problems of eco-friendly foods' market.

\subsection{Literature Review}

Several studies have stated consumers' concerns about environmentally certified or eco-friendly products. To investigate the demographic, psychological, and behavioral profiles of consumers who are willing to pay more for environmentally friendly products, economists and researchers used various statistical analyzes. The contingent valuation method (CVM) is a primarily used for monetary evaluation of consumer preferences for measuring food safety. Consumers' utility or WTP for quality goods are driven from a good's attributes, such as appearance, taste, and function. The choice modeling (CM) can be used to simulate real-world purchasing situation for the consumer wherein they will be required to choose their superior product from a set of options. The CM technique aims to classify a function of the attributes and labels so as to predict respondents' choice behavior. Concernig the consumers' purchase decision on the price premium related with the marginal utility of environmental food consumption. The price premium were represented that the consumers purchase environmentally certified commodities where the marginal benefits and marginal costs of environmental consumption are equal. To express the MWTP for each attribute of eco-friendly goods, the implicit prices for each of the attributes are used for a discrete change in an attribute level. Skreli et al. (2014) used the conjoint choice experiment (CCE) approach to find consumers' preferences for organic tomatoes in Albania. The results of this study revealed that the Albanian consumers preferred bio tomatoes to non-bio tomato and open field to greenhouse tomato, concerning the technology of tomato production. The study by Khai and Yabe (2015) applied the random parameter logit (RPL) model to estimate consumers' preferences for environmentally certified rice considering the value of biodiversity conservation in the Mekong Delta, Vietnam. This study stated that the majority of consumers in the study area primarily focused on the pesticide reduction attribute and they wanted to pay the highest premium for pesticide reduction relative to the other attributes. Additionally, the results of this study revealed that consumers' education and income levels, well knowledge about environmentally friendly farming techniques were influenced factors concerning their base purchase decisions and MWTP for eco-friendly rice. Wongprawmas and Canavari (2015) used the error component random parameter logit (RPL-EC) and latent class (CL) models to investigate the heterogeneity in consumer preferences for food safety labels in Thailand. This study stated that Thai consumers have a willingness to pay a high premium for food safety labels and brands, but they also have high heterogenity in their preferences. Concerning the freshness attribute, most consumers were tolerant to one-day-old produce than that is harvested two days ago. Ortega et al. (2011) conducted consumer preferences heterogeneity for select food safety attributes in China by using a random parameters logit (RPL) and latent class model (LCM). In this study, Chinese consumers attached a significant and postive value for food safety certification and highest WTP for government certification 
program among the food safety attributes. Concerning the findings of the existing literature, there has been little information on and few studies related to consumers' preferences and their willingness to pay for eco-friendly produce, especially for agricultural commodities in Myanmar. Min San (2016) explored the socio-economic study on consumers' preference for a standard for ensuring the safety of milk in Myanmar's fresh milk market. This study found that the majority of consumers in the urban area have positive significant marginal utility for pasteurized milk. Additionally, consumers were willing to pay more for pasteurized milk if the consumer has good knowledge about the pasteurized milk. Furthermore, the results of this study confirmed that the provision of complete label information is also one of the main factors that affect consumers' option.

\section{Method}

In this study, we used a choice experiment to examine the tomato consumers' preferences and MWTP for growing safe tomatoes. An environmentally friendly tomato is chosen as a target product because it is an essential culinary crop in Myanmar. Moreover, the heavy usage of pesticides in tomato floating gardens has threatened human health and the quality of the lake water. The choice modeling (CM) framework was used to estimate consumers' preferences for environmentally friendly tomato. The CM method is data generation approach that is based on carefully designed tasks or experiments that reveal the factors affecting choice. The specific attributes with their levels determine the good. These attributes would take under different management scenarios. Among these attributes, a monetary attribute can be used to estimate the welfare measure or value.

\subsection{Sampling Procedures and Survey Area}

The survey was conducted though a random face-to-face interview of consumers in the Yangon City, which is the former capital of and largest city in Myanmar. This urban area was selected because it is the economic heart of Myanmar in which rural and urban market for daily products. Moreover, the supermarkets in the Yangon region are more prevalent than in other regions and can get quality and safety foods.

\subsubsection{Sample Size}

The survey was conducted during August 2017. In total, 350 samples were collected, but 332 questionnaires could be completed for used in the data analysis. Data from 54\% respondents (179 persons) were collected at 4 open markets, and the data from the remaining $46 \%$ respondents (153 persons) were collected at 8 supermarkets in the downtown city. In Myanmar, open markets (or) fresh markets (or) wet markets are remained the favorite outlets for consumers for their daily foods especially vegetables even less hygienic than the supermarket. Therefore, we explored the open market consumers' attitude and preference that are contributed to a future environmentally friendly products market growth. The consumers were asked to participate in our survey on a voluntary basis.

\subsubsection{Sample Characteristics}

Descriptive statistics of the main socioeconomic characteristics of the respondents in the study area are shown in Table 1.

Table 1. Socioeconomic characteristics of the sampled respondents

\begin{tabular}{llll}
\hline Characteristics & Supermarket & Open Market & Pooled \\
\hline Gender (\%) & & & \\
Female & 86.93 & 86.03 & 86.45 \\
Male & 13.07 & 13.97 & 13.55 \\
Age (Mean, Std.dev.) & $37.43(12.34)$ & $41.88(12.19)$ & $39.83(12.39)$ \\
$\geq 60$ years (\%) & 2.61 & 7.82 & 5.42 \\
$<60$ years (\%) & 97.39 & 92.18 & 94.58 \\
Education level (Mean, Std.dev.) & $13.57(2.13)$ & $12.59(2.33)$ & $13.04(2.23)$ \\
Family size (Mean, Std.dev.) & $3.11(1.10)$ & $3.31(1.27)$ & $3.22(1.21)$ \\
Average household monthly income (Mean, Std.dev.) & $2.52(0.78)$ & $2.26(0.81)$ & $2.38(0.80)$ \\
Inc1 = less than 100,000 MMK/month (\%) & 5.88 & 14.53 & 10.54 \\
Inc2 = 100,000-499,999 MMK/month (\%) & 48.37 & 51.96 & 50.30 \\
Inc3 = 500,000-999,999 MMK/month (\%) & 33.99 & 26.26 & 29.82 \\
Inc4 = 1,000,000 MMK/month or more (\%) & 11.76 & 7.26 & 9.34 \\
Knowledge of environmentally friendly tomatoes (Mean, std.dev.) & $0.83(0.37)$ & $0.68(0.47)$ & $0.75(0.43)$ \\
\hline Total sample size & $\mathbf{1 5 3}$ & $\mathbf{1 7 9}$ & $\mathbf{3 3 2}$ \\
\hline
\end{tabular}

Note. 1 USD $=1,350$ MMK (Source: Central bank of Myanmar at 2018, May). 
Concerning the result of the descriptive data, the majority of respondents were female because, when compared to male members, most of the Myanmar women take responsibility of the consumption in their households and care about the diet of family members. Thus, female members exhibited an interest and patience to answer the questionnaires than male. The average age of respondents was 37.43 years in supermarket and 41.88 years in the open market. The younger consumers expressed a heightened interest to answer our questionnaires in both markets because only $5.42 \%$ of the total respondents comprised the elderly ( $\geq 60$ years old). The mean education level of respondents was 13.57 years in supermarkets and 12.59 years in the open market. The average family members were 3.22 persons. The average monthly household income in the study area was between $100,000-499,999 \mathrm{MMK} /$ month in the category, the respondents in the supermarket had a higher income than open markets' respondents. On average, about $33.99 \%$ and $11.76 \%$ of household incomes of supermarket respondents had income levels 3 and 4. According to the census data of the Yangon city, in 2014, the literacy rate in the Yangon Region is $96.6 \%$, and $38.57 \%$ of the Yangon residents had completed high school level and above. As expected from our target area, the majority of consumers belonged to the middle-class who generally has higher education level.

\subsubsection{Choice Experiment Questionnaire Design and Data Description}

To classify relevant food safety informational attributes, a pilot study was conducted in 2017 . Based on the pilot result, five attributes and their levels were selected for inclusion in the choice experiment: pesticide reduction (\%), gaining consumer trust with label, technology for tomato production, freshness and price. Table 2 illustrates detailed information on these attributes and their levels. Consumers prefer the pesticide reduction attribute owing to about their health concerns emerging from the proportion of pesticide residues on tomato. In order to identify the appropriate pesticide reduction level, the following two levels were used; $100 \%$ reduction (organic tomato) and at least $20 \%$ reduction (GAP tomato). According to GAP practices, the farm can use only proper pesticides and a standardized amount of agricultural chemicals. Hence, GAP tomato is assumed to reduce the use of pesticides and proportion of chemical residues by at least $20 \%$ than conventional tomato. In order to gain consumer trust, the producers, and retailers certified by the Myanmar Organic Agriculture Group (MOAG) and the Myanmar Organic Growers and Producers Association (MOGPA) are applying a label on the packaging of their organic products. The GAP tomato is being proposed to producers by the government. However, the rate of acceptance remains low, and only a small number of producers and retailers have been certified until now. For this attribute, we considered two types of tomato with and without a certified label. This classification is chosen because most of the vegetables are sold in the open market without packaging and labeling. Tomato is a highly seasonal crop; production peaks in the winter when slightly lower temperatures and moderate rainfall favor crop growth in the lowlands. Relatively cool temperatures and drier conditions in the Southern Shan State favor year round production of tomatoes because the lowland area can produce a little amount of tomato in the hot-dry (summer) months and hot-wet (rainy) months. Therefore, greenhouse production system can provide to consumers a sufficient amount of high-quality tomato in the off-season. Two types of technologies are commonly used in Myanmar to grow tomatoes: greenhouse production and field production. The freshness after harvest is denoted by days ( 0 days, 1 day, and 2 days). The highest freshness level is today ( 0 days). These levels of the freshness attribute can serve as an excellent illustration to explain to consumers about the freshness levels of tomato. For payment vehicle, the proposed tomato prices selected for the study are based on the data collected from the focus group, such as MMK 700, 1200, 1700 and 2200 per kg respectively. 
Table 2. Attributes and levels of environmentally friendly tomatoes used in the choice experiment

\begin{tabular}{|c|c|c|}
\hline Attribute & Description & Level \\
\hline Pesticide reduction $(\%)$ & $\begin{array}{l}\text { Refers to the usage of chemical pesticides for tomato } \\
\text { production. }\end{array}$ & $\begin{array}{l}2 \text { Levels: } \\
100 \% \text { reduction, Organic Tomato } \\
\text { At least } 20 \% \text { reduction, GAP tomato }\end{array}$ \\
\hline Gaining consumer trust through labels & $\begin{array}{l}\text { Refers to the usage of the certified logo on tomato is assumed } \\
\text { by the Ministry of Agriculture, Livestock and Irrigation, } \\
\text { Myanmar and Myanmar organic agriculture. }\end{array}$ & $\begin{array}{l}2 \text { Levels: } \\
\text { With certified label } \\
\text { Without certified label }\end{array}$ \\
\hline Technology for tomato production & $\begin{array}{l}\text { Refers to the type of techniques used to cultivate tomato. It is } \\
\text { one of the most important factors for ensuring the availability } \\
\text { of high-quality seasonal products, especially tomato, } \\
\text { throughout the year }\end{array}$ & $\begin{array}{l}2 \text { Levels: } \\
\text { Greenhouse tomato } \\
\text { Field tomato }\end{array}$ \\
\hline Freshness (the day after harvest) & $\begin{array}{l}\text { Refers to the freshness level of tomato. It is one of the } \\
\text { important factors that influence consumers' decision when } \\
\text { buying a tomato. }\end{array}$ & $\begin{array}{l}3 \text { Levels: } \\
0 \text { days (Today) } \\
1 \text { day (Yesterday) } \\
2 \text { days ( } 2 \text { days before) }\end{array}$ \\
\hline $\begin{array}{l}\text { Price }(\mathrm{MMK} / \mathrm{kg}) \\
1 \mathrm{USD}=1300 \mathrm{MMK} \\
1 \mathrm{Yen}=12 \mathrm{MMK}\end{array}$ & $\begin{array}{l}\text { Indicates the price for } 1 \mathrm{~kg} \text { tomato that the consumer wants to } \\
\text { pay for environmentally friendly tomato. }\end{array}$ & $\begin{array}{l}4 \text { Levels: } \\
\text { MMK } 700 \\
\text { MMK } 1200 \\
\text { MMK } 1700 \\
\text { MMK } 2200\end{array}$ \\
\hline
\end{tabular}

Subsequently, we used the selected attributes and their levels to design the choice experiment. The "opt-out" or the no-buy option was provided for allowing the consumers to opt-out buying any available choices in the real shopping situation (Adamowicz et al., 1998; Gao \& Schroeder, 2009; Loureiro \& Umberger, 2007; Lusk \& Schroeder, 2004). Experimental design techniques were used with the SPSS conjoint software to obtain an orthogonal design consisting of only the main effects, which resulted in 32 pair-wise comparisons of an alternative. Based on these choice sets, four versions of the choice experiment questionnaire were developed. Table 3 is described as the example of a choice set. Before introducing the choice experiment sets, the information regarding each considered attributes of environmentally friendly tomatoes was given to respondents (Appendix A describes the proposed tomatoes and more detailed information). Respondents were informed that the tomatoes presented to them differ only on the basis of the five attributes described and that all other attributes are identical. The choice questions were given to prevent systematic order effects in randomized order across respondents (Loureiro \& Umberger, 2007). The questionnaire contained choice experiment questions and other questions concerning consumers' attitudes, their knowledge of food safety and environmental friendly tomatoes, consumption patterns, and respondents' socioeconomic information. The closed-form and multiple choices were used. In the attitudes section, respondents were asked to give their opinions on statements according to a 5-point Likert-like scale, ranging from 1 (Strongly disagree) to 5 (Strongly agree). Later, respondents were asked to choose their preferable alternative between the two options of environmental friendly tomato and an opt-out option.

Table 3. Sample question of choice set profile in questionnaire

\begin{tabular}{|c|c|c|c|}
\hline Attribute & Option A & Option B & Option $\mathrm{C}$ \\
\hline Pesticide reduction $(\%)$ & $\begin{array}{l}\text { At least } 20 \% \text { reduction, } \\
\text { GAP tomato }\end{array}$ & $100 \%$ reduction, Organic tomato & Choose the tomato I usually buy \\
\hline Gaining consumers' trust through labels & Without certified logo & With certified logo & \\
\hline Technology for tomato production & Field tomato & Greenhouse tomato & \\
\hline Freshness (the day after harvest) & 0 days (Today) & 1 day (Yesterday) & \\
\hline Price $(\mathrm{MMK} / \mathrm{kg})$ & MMK 1200 & MMK 1700 & \\
\hline I would like to choose (Tick only one) & $\square$ & $\square$ & $\square$ \\
\hline
\end{tabular}

\subsection{Theoretical Framework and Econometric Model}

The CM technique was first developed by Louviere and Hensher (1982); later, was widely applied in the fields of marketing, transportation, and tourism (Carson et al., 1995). The CM method was initially developed from the conjoint analysis, but it differed from typical conjoint methods because it asked respondents to select one 
alternative from choice sets of attributes instead of ranking or rating them. The theory of choice experimental design is applied to build profiles of the good pertaining to its attributes and attribute levels. Subsequently, two or three alternative profiles are assembled in choice sets and introduced to respondents, who are requested to state their preferred profile in each choice set. Owing to its consistency with random utility theory, CM has been used to estimate the passive use values of environmental goods (Adamowicz et al., 1998). Choice experiments are theoretically grounded in the Lancaster's theory of consumer choice (Lancaster, 1966) and econometrically based on the Random Utility Model (RUM) (McFadden, 1974; Thurstone, 1927). The advantages of using choice experiments over other revealed preference experimental methods have been documented in several studies, including its conformity to random utility theory and Lancaster's approach to consumer theory (Lusk \& Schroeder, 2004; Carlsson et al., 2007).

Choice experiments are based on the statement that individual $i$ obtains utility $(U)$ from selecting alternative $j$ from a finite set of $J$ alternatives contained in the choice set $C$ in situation $t$. The utility is comprised of a deterministic component $\left(V_{i j}\right)$ that depends on the attributes of an alternative and a stochastic component $\left(\varepsilon_{i j}\right)$. The utility of alternative $i$ can be specified as,

$$
U_{i j t}=V_{i j t}+\varepsilon_{i j t}
$$

Therefore, individual $i$ will choose alternative $j$ if $U_{i j}>U_{i k} ; \forall k \neq j$. The probability of individual $i$ choosing alternative $j$ is given by,

$$
\operatorname{Prob}_{i j t}=\left[\operatorname{Prob}\left(V_{i j t}+\varepsilon_{i j t}\right)>\left(V_{i k t}+\varepsilon_{i k t}\right) ; \forall k \in C, \forall k \neq j\right]
$$

The assumptions about the distribution of error terms that are implicit in the use of the conditional logit (CL) model impose a particular condition known as the independence of irrelevant alternatives (IIA) property, which states that the relative probabilities of two options being chosen are unaffected by the introduction or removal of other alternatives. The study uses a Hausman and Mcfadden (1984) test to check whether the IIA property is violated. Another assumption required for appropriate model specification of the CL model is that preferences are homogeneous across respondents.

If the IIA property is violated or if there are heterogeneous preferences across respondents, then the CL model's results would become biased. The random parameter logit (RPL) model, which does not require the IIA assumption and can also account for unobserved and unconditional heterogeneity in preferences across respondents, may be applied. The random parameter logit is a highly flexible model that can estimate any random utility model and relax the limitations of the traditional logit by allowing random taste variation within a sample according to a specified distribution (McFadden \& Train, 2000). Under RPL, the deterministic component of utility $\left(V_{i j}\right)$ in the random utility model takes the form of,

$$
V_{i j t}=\beta_{i}^{\prime} X_{i j t}
$$

where, $X_{i j}$ is a vector of attributes found in the alternative $j$ and individual $i$ in choice situation $t, \beta_{i}^{\prime}$ is a vector of random parameters for respondent $i$ representing the individual preferences. The probability that individual $i$ choose alternative $j$ from the choice set $\mathrm{C}$ in situation $t$ (Train, 2003) is given by,

$$
\operatorname{Prob}_{i j t}=\int\left[\frac{\exp \left(\beta_{i}^{\prime} X_{i j t}\right)}{\sum_{k \in C} \exp \left(\beta_{i}^{\prime} X_{i k t}\right)}\right] f(\beta) d \beta
$$

The coefficients vary over respondents with density $f(\beta)$, where $f(\beta)$ is specified to be normal $\beta \sim N(b, W)$ with parameters $\mathrm{b}$ and $\mathrm{W}$ that are estimated.

\section{Results}

\subsection{Test of Independence of the Irrelevant Alternatives (IIA)}

To conduct an empirical analysis of the present study, NLOGIT 5.0 is used. A total of 2656 choices are elicited from 332 respondents. Owing to the limitations of the conditional logit model, we considered a benchmark model to test the hypothesis of preference heterogeneity across consumer choices. Concerning the assumption about the distribution of error terms, we used a test by Hausman and McFadden (1984) to check whether the independence of the irrelevant alternatives (IIA) property is violated. This property states that the ratio of the probabilities of choosing any two options is independent by inclusion or exclusion of other alternatives in the choice set (Hausman \& McFadden, 1984). The results of IIA test for the present study are reported in Table 4. The critical value of the Chi-square distribution which is 18.48 at $1 \%$ significance level on seven degrees of freedom is significantly lower than the values of test statistics. It is suggested that a less-restrictive specification of the choice model which relaxes the IIA property must be considered. 
Moreover, the conditional logit model assumes the preference homogeneity across respondents, however, consumer preferences are found to be almost heterogeneous in the real situation. Thus, the random parameter logit (RPL) or mixed logit model is applied for conducting data analysis of the present study. We estimate the RPL model with simulated maximum likelihood using Halton draws. Alternative-specific constant (ASC) for the two alternatives of environmentally friendly tomato is included. Since the distribution of the MWTP for an attribute is the distribution of that attribute's coefficient, this inclusion will keep the price attribute fixed and not randomly distributed (Carlsson et al., 2007; Train, 2003). The non-price attributes (Organic, Label, Tech, Fresh1, and Fresh2) are all randomly distributed with a normal distribution. In the RPL model, socioeconomic characteristics of respondents such as income, family size, age and knowledge about the eco-friendly tomatoes are included as fixed coefficients. These variables interact with ASC, while some variables are involved with attributes. These interactions exposed the effects of socioeconomic characteristics on the probability of respondents' choices either option A or option B.

Table 4. Test of Independence of irrelevant alternatives (IIA)

\begin{tabular}{llll}
\hline Alternative dropped & $\chi^{2}$ & Degree of freedom & Probability \\
\hline Option A & 438.4161 & 7 & 0.0000 \\
Option B & 160.0415 & 7 & 0.0000 \\
\hline
\end{tabular}

\subsection{Results of RPL model}

Variables and their representative codes used in RPL model are presented in Table 5.

Table 5. Variables included in the random parameter logit (RPL) model analysis

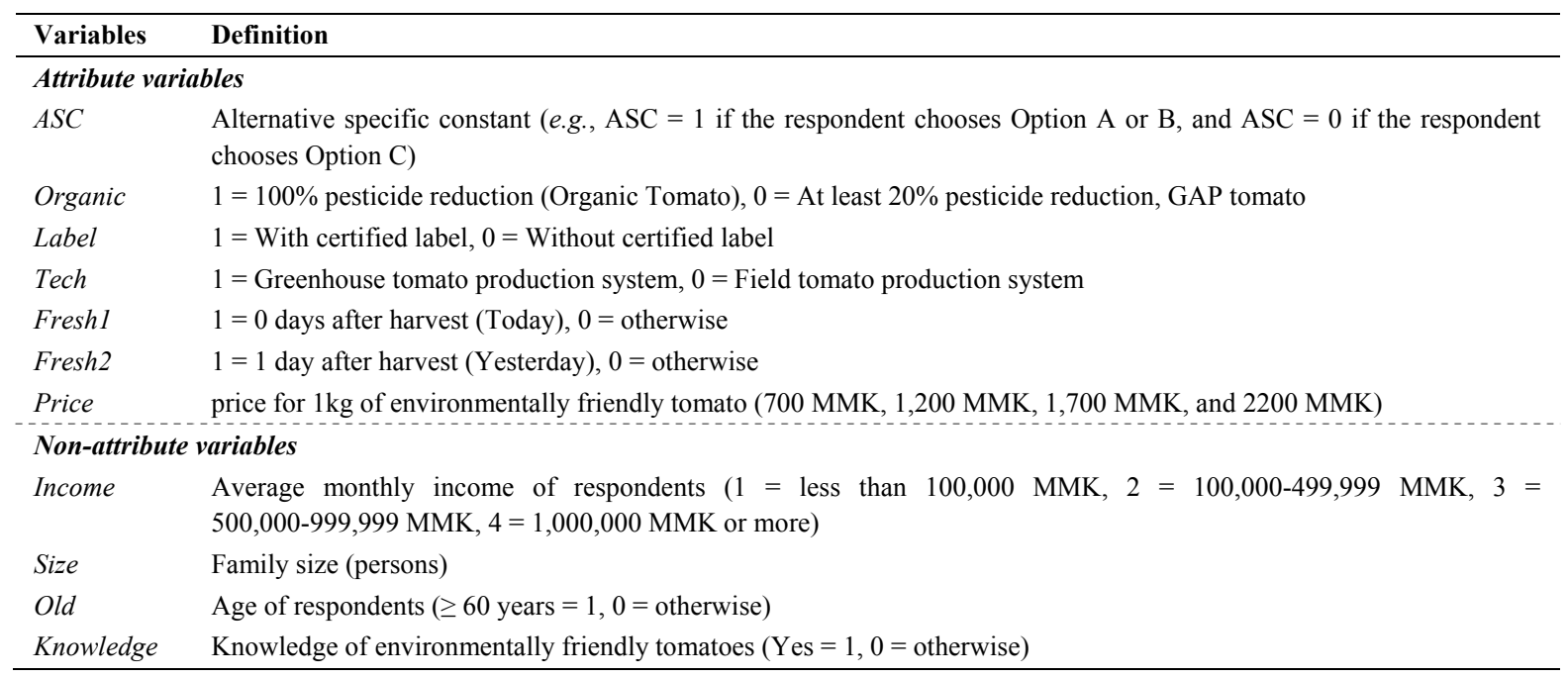

The results of the RPL model estimation for respondents in the supermarket and, open market and the pooled data set are presented in Table 6 . All parameters in the RPL model are statistically significant at the $1 \%$ level; it indicates that all attributes are significant factors for finding consumer preferences for the environmental friendly tomato. The positive sign of the ASC coefficient describes that the consumer utility for option A and option B that represented the environmentally friendly tomato is higher than that of the conventional tomato. The price variables are statistically significant with the negative sign. It means that increasing the price of environmental friendly tomatoes leads to a reduction in consumer utility and lowers the possibility of purchase. RPL models estimation for supermarket and open market respondents are statistically significant at the $1 \%$ level with $X^{2}$ statistics of 1791.7132 and 2253.7712 against a critical value of 26.217 with 12 degrees of freedom. Moreover, the estimation for both datasets from the supermarket and open market areas is also statistically significant at the $1 \%$ level, with $X^{2}$ statistics of 3921.0797 against a critical value 26.217 with 12 degrees of freedom. By comparing the value of the log-likelihood (LL) ratio of the pooled model $(L L=-957.3744)$ against the separate models for supermarket respondents $(L L=-448.8449)$ and open market respondents $(L L=-446.3272)$ is estimated at 124.4046, which is greater than the critical value of the $X^{2}$ distribution of 26.217 with 12 degrees of 
freedom. The null hypothesis is that there are no separate effects of the two data sets that are rejected at the 5\% significance level (Arbiol et al., 2015; Louviere et al., 2000; Swait \& Louviere, 1993).

$$
\text { Log Likelihood Ratio }=-2\left[L L_{\text {pooled model }}-\left(L L_{\text {Supermarket }}+L L_{\text {Open market }}\right)\right]
$$

Therefore, it is not appropriate to investigate the consumer preference for environmentally friendly tomato in the study area through pooled data. There are different preferences for proposed tomato attributes between supermarket respondents and open market respondents.

Table 6. Estimated results of the Random Parameter Logit (RPL) model

\begin{tabular}{|c|c|c|c|c|c|c|c|c|c|}
\hline \multirow{2}{*}{ Variables } & \multicolumn{3}{|c|}{ Supermarket } & \multicolumn{3}{|c|}{ Open Market } & \multicolumn{3}{|c|}{ Pooled Data } \\
\hline & \multicolumn{2}{|c|}{ Coefficient } & \multirow[t]{2}{*}{ Std. error } & \multicolumn{2}{|c|}{ Coefficient } & \multirow[t]{2}{*}{ Std. error } & \multicolumn{2}{|c|}{ Coefficient } & \multirow[t]{2}{*}{ Std. error } \\
\hline Random parameter & & & & & & & & & \\
\hline Organic & 2.3739 & $* * *$ & 0.4513 & 3.5022 & $* * *$ & 0.4812 & 2.2792 & *** & 0.2137 \\
\hline Label & 7.3336 & $* * *$ & 1.5117 & 9.6988 & $* * *$ & 1.3003 & 6.0607 & $* * *$ & 0.5031 \\
\hline Tech & 0.9605 & $* * *$ & 0.2545 & 1.5429 & $* * *$ & 0.3107 & 0.9775 & $* * *$ & 0.1493 \\
\hline Fresh1 & 3.0504 & $* * *$ & 0.5647 & 3.3806 & $* * *$ & 0.4534 & 2.5927 & $* * *$ & 0.2471 \\
\hline Fresh2 & 1.9476 & $* * *$ & 0.3817 & 1.8374 & $* * *$ & 0.3960 & 1.5606 & $* * *$ & 0.2145 \\
\hline \multicolumn{10}{|l|}{ Fixed parameters } \\
\hline$A S C$ & 6.7787 & $* * *$ & 0.8550 & 10.3037 & $* * *$ & 1.2406 & 5.8946 & $* * *$ & 0.3885 \\
\hline Price & -0.0032 & $* * *$ & 0.0004 & -0.0075 & $* * *$ & 0.0009 & -0.0039 & $* * *$ & 0.0003 \\
\hline \multicolumn{10}{|c|}{ Standard deviations for random parameters } \\
\hline Organic & 1.9738 & $* * *$ & 0.6888 & 3.2911 & $* * *$ & 0.7089 & 1.9586 & $* * *$ & 0.3063 \\
\hline Label & 5.3354 & $* * *$ & 1.4117 & 5.1356 & $* * *$ & 0.8945 & 3.4599 & $* * *$ & 0.4507 \\
\hline Tech & 0.6728 & & 0.4807 & 0.3115 & & 0.3687 & 0.2099 & & 0.2772 \\
\hline Fresh1 & 0.3209 & & 0.3347 & 0.0714 & & 0.3347 & 0.1084 & & 0.2225 \\
\hline Fresh2 & 0.1943 & & 0.3813 & 0.0178 & & 0.3331 & 0.0725 & & 0.2696 \\
\hline Pseudo $R^{2}$ & 0.6662 & & & 0.7163 & & & 0.6719 & & \\
\hline Log likelihood & -448.84 & & & -446.327 & & & -957.37 & & \\
\hline No of parameters & 12 & & & 12 & & & 12 & & \\
\hline$\chi^{2}$ & 1791.71 & & & 2253.771 & & & 3921.07 & & \\
\hline No of Observation & 1224 & & & 1432 & & & 2656 & & \\
\hline
\end{tabular}

Note. ${ }^{* * *}, * *$ and $*$ indicate significance level at $1 \%, 5 \%$ and $10 \%$ respectively.

According to the interactions of respondents' characteristics, the results of RPL model with interactions of supermarket and open market respondents in the urban area of the Yangon city are shown in Table 7. The RPL model with interactions of both markets also indicates that, by contributing a specific recommendation to each group of respondents, all the attribute coefficients become statistically significant at the $1 \%$ and $5 \%$ levels. The model with interactions reports that the younger respondents in supermarkets prefer to choose organic tomato (100\% chemical pesticides reduction) than the elderly because the interactions between ASC and the age of respondents is negatively significant at the $1 \%$ level. Subsequently, significant and positive coefficients of interaction variables between ASC and monthly household income in both markets located at the center of the city indicate that the respondents who earn higher income have a higher WTP and are more likely to accept the proposed environmentally friendly tomatoes. In supermarket and open market, the respondent who has large family size is less likely to prefer the environmentally friendly tomatoes as regards the significantly negative relationship between ASC and family size. In supermarkets, the respondents who are familiar with the environmentally friendly production systems have a high preference to purchase organic tomato. However, the respondents in the open market who familiar with the environmentally friendly production systems show high preference toward environmental friendly tomatoes having the certified label and highest freshness level. 
Table 7. Estimated results of RPL model with interaction terms

\begin{tabular}{|c|c|c|c|c|c|c|}
\hline \multirow{2}{*}{ Variables } & \multicolumn{3}{|c|}{ Supermarket } & \multicolumn{3}{|c|}{ Open Market } \\
\hline & \multicolumn{2}{|c|}{ Coefficient } & \multirow[t]{2}{*}{ Std. error } & \multicolumn{2}{|c|}{ Coefficient } & \multirow[t]{2}{*}{ Std. erro1 } \\
\hline \multicolumn{5}{|l|}{ Random parameters } & & \\
\hline Organic & 1.5095 & $* *$ & 0.6050 & 2.8309 & $* * *$ & 0.5097 \\
\hline Label & 6.6236 & $* * *$ & 1.5958 & 6.4655 & $* * *$ & 0.9721 \\
\hline Tech & 1.1831 & $* *$ & 0.5196 & 1.4973 & $* * *$ & 0.4564 \\
\hline Fresh1 & 2.9914 & $* * *$ & 0.7728 & 2.4018 & $* * *$ & 0.5250 \\
\hline Fresh2 & 1.3725 & $* *$ & 0.5549 & 1.1760 & $* *$ & 0.5173 \\
\hline \multicolumn{7}{|l|}{ Fixed parameters } \\
\hline$A S C$ & 6.9916 & $* *$ & 3.1831 & 4.6154 & $* * *$ & 1.3700 \\
\hline Price & -0.0032 & $* * *$ & 0.0004 & -0.0069 & $* * *$ & 0.0008 \\
\hline ASC ${ }^{*}$ Income & 2.6898 & $* *$ & 1.2631 & 3.9208 & $* * *$ & 0.5953 \\
\hline ASC*Size & -1.5120 & $* * *$ & 0.5107 & -0.7156 & $* * *$ & 0.2363 \\
\hline Organic* Old & -3.4880 & $* *$ & 1.7589 & 0.1810 & & 0.8315 \\
\hline Label*Old & 0.9421 & & 1.8021 & -1.5262 & & 1.0205 \\
\hline Tech*Old & 0.0189 & & 1.2804 & -0.0240 & & 0.8577 \\
\hline Fresh $1 *$ Old & 2.3102 & & 2.4177 & -0.3249 & & 0.9470 \\
\hline Fresh $2 *$ Old & -0.1322 & & 1.3657 & -0.8919 & & 1.0188 \\
\hline Organic*Knowledge & 1.4868 & $* *$ & 0.6500 & 0.4410 & & 0.5203 \\
\hline Label*Knowledge & 1.3170 & & 1.0719 & 3.2061 & $* * *$ & 0.7305 \\
\hline Tech*Knowledge & -0.2174 & & 0.5373 & 0.4203 & & 0.5059 \\
\hline Fresh $1 *$ Knowledge & 0.1424 & & 0.7437 & 1.5922 & $* * *$ & 0.5925 \\
\hline Fresh $2 *$ Knowledge & 0.7652 & & 0.5845 & 0.7540 & & 0.5958 \\
\hline \multicolumn{7}{|c|}{ Standard deviations for random parameters } \\
\hline Organic & 1.8479 & $* * *$ & 0.5444 & 2.7846 & $* * *$ & 0.6739 \\
\hline Label & 5.8437 & $* * *$ & 1.3522 & 3.4777 & $* * *$ & 0.7353 \\
\hline Tech & 0.1890 & & 0.4028 & 0.4414 & & 0.3828 \\
\hline Fresh1 & 0.1313 & & 0.3518 & 0.0398 & & 0.3410 \\
\hline Fresh2 & 0.0045 & & 0.3450 & 0.0361 & & 0.3404 \\
\hline Pseudo $R^{2}$ & 0.6816 & & & 0.7601 & & \\
\hline Log likelihood & -428.171 & & & -377.46 & & \\
\hline No of parameters & 24 & & & 24 & & \\
\hline$\chi^{2}$ & 1833.06 & & & 2391.49 & & \\
\hline No of Observation & 1224 & & & 1432 & & \\
\hline
\end{tabular}

Note. ${ }^{* * *},{ }^{* *}$ and $*$ indicate significance at the $1 \%, 5 \%$ and $10 \%$ levels, respectively.

\subsection{Implicit Price or Marginal Willingness to Pay}

To identify the MWTP as a result of a distinct change in an attribute level, we used the implicit prices for each of the non-price attributes of environmentally friendly tomatoes. This price enables us to understand the relative importance that the consumers give to attributes within the design. The following equation estimates the implicit price of each attribute levels:

$$
\text { Implicit price for attribute }=-\left(\frac{\beta_{\text {attribute }}}{\beta_{\text {Price }}}\right)
$$

Table 8 contains the results of the implicit prices or marginal WTP for each attribute of environmentally friendly tomato with corresponding $95 \%$ confidence intervals. The consumers in both markets have a high WTP for each attribute because the results of implicit prices for all attribute are positive. The implicit price of the pesticide reduction attribute, the consumers are willing to pay a premium of 471.109 MMK (0.35 USD) in the supermarket and 409.012 MMK (0.30 USD) in open market for $1 \mathrm{~kg}$ of organic tomato or for a $100 \%$ pesticide-free produce. Interestingly, the consumers in the supermarket pay considerable attention to the certified label attribute. Concerning the implicit prices for the certified label attribute, supermarket consumers want to spend an additional 2067.170 MMK (1.53 USD) per kg. However, the MWTP of open market consumers is 934.140 MMK per kg extra for the certified label attribute. The respondents agree to pay a premium for the technology attribute; the premium is 369.277 MMK (0.27 USD) and 216.333 MMK (0.16 USD) in the 
supermarket and open market, respectively. The respondents in the supermarket have an additional WTP of 933.587 MMK (0.69 USD) per kg for environmental friendly tomatoes with highest freshness level attributes and 428.337 MMK (0.32 USD) per kg for freshness2 attributes.

Table 8. Implicit prices for each attribute of environmentally friendly tomato in both markets of the Yangon city

\begin{tabular}{lll}
\hline Attribute & Supermarket & Open Market \\
\hline Organic & $471.109^{* * *}(120.253 \sim 821.965)$ & $409.012^{* * *}(285.182 \sim 532.841)$ \\
Label & $2067.170^{* * *}(1257.610 \sim 2876.730)$ & $934.140^{* * *}(761.803 \sim 1106.478)$ \\
Tech & $369.227^{* *}(66.316 \sim 672.138)$ & $216.333^{* * *}(97.588 \sim 335.077)$ \\
Fresh1 & $933.587^{* * *}(512.522 \sim 1354.652)$ & $347.010^{* * *}(210.956 \sim 483.064)$ \\
Fresh2 & $428.337^{* * *}(105.567 \sim 751.107)$ & $169.906^{* *}(28.266 \sim 311.545)$ \\
\hline
\end{tabular}

Note. $* * *, * *$ and $*$ indicate significance at the $1 \%, 5 \%$, and $10 \%$ levels, respectively; figures in parentheses are $95 \%$ confidence of intervals.

\section{Discussion and Conclusions}

This study uses a choice experiment approach to analyze Myanmar's consumer preferences and their marginal WTP forming attributes that are related to the proposed tomatoes. Subsenquently, we explore the factors affecting the probability of demanding eco-friendly farming techniques comprising organic farming and good agriculture practices. This study revealed that the majority of consumers in both markets of the Yangon city are concerned about food safety and are willing to pay more to assure that their daily food is safe. Thus, the majority of respondents were willing to pay a higher premium for an environmentally certified tomato that had reduced levels of pesticides, especially organic tomato or $100 \%$ pesticide-free tomatoes. This evidence is also highlighted in the study by Khai and Yabe (2015) that consumers are highly concerned about their health and food safety. Moreover, this study showed that the majority of consumers prefer complete label information based on reliable certification when they choose environmentally friendly tomato in the market. This result is consistent with previous studies on food safety in the Yangon city by Min San., (2016) that complete label information is also the critical factor that affects consumers' options. As a result, the consumers in the study area also consider freshness and price of the product when making their purchase decisions for tomato. According to the results on MWTP, most of the respondents in both markets had a positive WTP for an increase in each attribute. As we expected, the supermarket respondents were willing to pay more for environmentally friendly tomato; this factor is revealed by comparing the MWTP of open market respondents. Moreover, the supermarket respondents paid attentions to food safety labels; for this attribute, the MWTP of supermarket respondents was the highest at 2067.170 MMK (1.53 USD), when compared to the other attributes. However, the maximum additional WTP of open market respondents was 934.140 MMK (0.69 USD) for an eco-friendly tomato with certified labels. This study reveals that the open market consumers were highly concerned about food safety and preferred to purchase environmentally friendly tomato.

Concerning the results of the interaction variables in both supermarket and open market, the consumers who have higher income are more likely to prefer environmentally friendly tomatoes because they do not pay attentions to the price attribute but focus only on quality and safety attributes. This result indicates that consumers' knowledge of the eco-farming systems also contributes to the development of a market for environmentally certified products. Consistent with the results by Khai and Yabe (2015), this study stated that the consumer who has more information or high knowledge preferred the proposed rice that is cultivated using environmentally friendly farming techniques. Additionally, concerning pesticide reduction and label attributes, our results in the RPL model revealed the signs of heterogeneity among respondents' preferences in the supermarket and open market. This research found that consumers' preferences differ between pesticide reduction and label attributes.

Our findings showed that most of the consumers paid attentions to food safety labels and had the highest MWTP relative to the other attributes. To develop eco-friendly products market, producers and marketers should apply food safety certifications and labels as a tool to differentiate products. The results of this study also suggest the environmentally friendly tomato producers and marketers that there is a perceived need to express the level of freshness in the fresh produce supply chain. Consumers' MWTP showed that there is a large potential market for certified environmental products in the Yangon City. Moreover, a higher MWTP of consumers may provide an incentive to local eco-friendly producers for shifting from conventional to environmentally friendly farming 
systems. However, consumers' preferences for pesticides reduction level $(100 \%$ reduction, organic or at least $20 \%$ reduction, GAP) and certified labels (with or without) were heterogeneous in both markets of the Yangon City. There was a difference in the focus of tomato consumers in the study area on chemical residues on the product and the trusted labels when they choose tomatoes in the market.

Our results suggest policymakers and producers that they must to increase consumers' knowledge about what is an eco-product and how to differentiate between an eco-product and conventional product in the market place. The policymakers and stakeholder should consider focusing on not only supermarkets but also open markets in the city and conduct educational or promotional programs about the benefits of environmentally friendly agricultural products. Producers and marketers should use advertising or merchandise strategies to improve consumers' understanding and recognition of trademarks. For example, they can use various media, such as the Internet, television, radio, and newspapers. The government and authorizing bodies of food safety certification programs should emphasize on the improvement of the ecofriendly certifications and enhance the trust of consumers with the certification and labels.

The limitation of this study is that we focused only on with or without certified labels or logo on the environmental friendly tomatoes to explore factor affecting consumers' reliability. We cannot dismiss the effects of different types of certified labels. In this study, we could only know that the effects of eco-labeling programs for agricultural commodities are vital when consumers choose environmentally friendly tomatoes in the market. In a further study, the different types of certified label or logo could be added in the experimental design to identify which types of certified label are more trusted or preferred by consumers. In this study, the results were based on the city of Yangon; this might not be representative of Myanmar consumers' preferences. For planning and applying more effective policies to develop a market for environmentally certified products, our results might not be enough to aid policy makers. However, the results can be referred for further research of other environmentally friendly products and can be extended to another area of Myanmar with a bigger sample size. In this study, the possible important determinates of consumers' preferences, such as lifestyles variables, could not be mentioned. Hence, the future studies can determine consumers' preference by adopting segmentation approaches of consumer lifestyles by using latent class modeling.

\section{Acknowledgements}

We would like to express our gratitude to the responsible persons from the Japan International Cooperation Agency (JICA) for providing finance and various kind supports when our studied in this research. We are also grateful to all the lab mates and staffs in Laboratory of Environmental Economics in Kyushu University for sharing their knowledge and ideas to complete the research. Our warmest thanks go to the teachers, colleges and final year students of Department of Agricultural Economics, Yezin agricultural University for kind contributions during our survey period.

\section{References}

Adamowicz, W., Boxall, P., Williams, M., \& Louviere, J. (1998). Stated preference approaches for measuring passive use values: Choice experiments and contingent valuation. American Journal of Agricultural Economics, 80(1), 64-75. https://doi.org/10.2307/3180269

Carson, R. T., Wright, J., Carson, N., Alberini, A., \& Flores, N. (1995). A bibliography of contingent valuation studies and papers: Natural resource damage assessment. La Jolla, CA.

Carlsson, F., Frykblom, P., \& Lagerkvist, C. J. (2007). Consumer benefits of labels and bans on GM foods -Choice experiments with Swedish consumers. American Journal of Agricultural Economics, 89(1), 152-161. https://doi.org/10.1111/j.1467-8276.2007.00969.x

Gorton, M., Sauer, J., \& Supatpongkul, P. (2009). Investigating Thai Shopping Behavior: Wet-Markets, Supermarkets and the 'Big Middle'. Paper presented at the International Association of Agricultural Economists, Beijing, China.

Hausman, J., \& McFadden, D. (1984). Specification tests for the multinomial logit model. Econometrica, 52(5), 1219-1240. https://doi.org/10.2307/1910997

Khai, H. V., \& Mitsuyasu, Y. (2015). Consumer Preferences for Agricultural Products Considering the Value of Biodiversity Conservation in the Mekong Delta, Vietnam. Journal for Nature Conservation, 25, 62-71. https://doi.org/10.1016/ j.jnc. 2015.02.004

Kyaw, E. M. T. (2014). Determinants of Environmental Awareness Index and Pesticide Demand of Tomato Famers in Inle Lake (Master's thesis, Yezin Agriculture University, Naypyitaw, Myanmar). 
Lancaster, K. J. (1966). A new approach to consumer theory. Journal of Political Economy, 71, 25. https://doi.org/10.1086/259131

Loureiro, M. L., \& Umberger, W. J. (2007). A choice experiment model for beef: What US consumer responses tell us about relative preferences for food safety, country-of-origin labeling and traceability. Food Policy, 32(4), 496-514. https://doi.org/10.1016/j.foodpol.2006.11.006

Louviere, J. J., \& Hensher, D. A. (1982). Design and analysis of simulated choice or allocation experiments in travel choice modeling. Transportation Research Record, 890, 7.

Louviere, J. J., Hensher, D. A., \& Swait, J. D. (2000). Stated choice methods: analysis and applications. Cambridge University Press. https://doi.org/10.1017/CBO9780511753831

Lusk, J. L., \& Hudson, D. (2004). Willingness-to-Pay Estimates and Their Relevance to Agribusiness Decision Making. Review of Agricultural Economics, 26(2), 152-169. https://doi.org/10.1111/j.1467-9353.2004. 00168.x

McFadden, D. (1974). Conditional logit analysis of qualitative choice behavior. In P. Zarembka (Ed.), Frontiers in econometrics. New York, NY: Academic Press.

McFadden, D., \& Train, K. (2000). Mixed MNL models for discrete response. Journal of Applied Econometrics, 15(5), 447-470. https://doi.org/10.1002/1099-1255(200009/10)15:5\%3C447::AID-JAE570\%3E3.0.CO;2-1

MOALI (Ministry of Agriculture and Irrigation). (2017). Myanmar Agriculture in Brief. Department of Agricultural Planning, Ministry of Agriculture and Irrigation, Myanmar.

Min, S. (2016). Socio-economic study on consumers' preference towards certificate for development of safety milk in Myanmar fresh milk market (Master's Thesis, Environmental Economic Laboratory, Graduate School of Bio-resource and Bioenvironmental Science, Kyushu University).

Olynk, N., Tonsor, G., \& Wolf, C. (2010). Consumer willingness to pay for livestock credence attribute claim verification. Journal of Agricultural and Resource Economics, 35(2), 261-280.

Ortega, D. L., Holly, W., L. W., \& Nicole, J. O. (2011). Modeling Heterogeneity in Consumer Preferences for Select Food Safety Attributes in China. Food Policy, 36(2), 318-24. https://doi.org/10.1016/j.foodpol. 2010.11.030

Pimentel, D., Acquay, H., Biltonen, M., Rice, P., Silva, M., Nelson, J.,... M. D’Amore. (1992). Environmental and human costs of pesticide use. Bioscience, 42, 750-760. https://doi.org/10.2307/1311994

Pire, E. (2014). Consumers' Preferences for Organic Food Applying Conjoint Analysis-the Case of Tomato in Albania, no. 11, 1-14.

Skreli, E., Drini, I., Maurizio, C., Catherine, C-H., Edvin, Z., \& Ergent, P. (2014). Consumers' Preferences for Organic Food Applying Conjoint Analysis-The case of Tomato in Albania (No. 11, pp. 1-14). 24th Annual IFAMA World Forum and Symposium, People Feed the World: The Talent Factor. June 16-17, 2014, Cape Town. Retrieved from https://www.ifama.org/resources/files/2014-Conference/1037.pdf.

Swait, J. D., \& Louviere, J. (1993). The role of the scale parameter in the estimation and comparison of multinomial logit models. J. Mark. Res., 30, 305-314. https://doi.org/10.1177/002224379303000303

Thurstone, L. L. (1927). A Law of Comparative Judgment. Psychological Review, 4, 273-286. https://doi.org/ $10.1037 / \mathrm{h} 0070288$

Train, K. (2003). Discrete choice methods with simulation. Cambridge University Press. https://doi.org/ $10.1017 / \mathrm{CBO} 9780511753930$

Wongprawmas, R., \& Canavari, M. (2015). Heterogeneity in Consumer Preferences for Food Safety Label in Thailand. Naples, Italy. Retrieved from http://ageconsearch.umn.edu/bitstream/202744/2/236.pdf 


\section{Appendix A}

The hypothetical scenario of the proposed tomato and CM question is presented below.

Section 3: General Knowledge of Environmentally Friendly Product

(1) Have you ever heard/observed about environmentally friendly tomato (organic or good agriculture practices)?

1. Yes, I know; 2. No, I do not know.

(2) Have you ever heard/observed about certification of environmentally friendly tomato in our country?

1. Yes, I know; 2. No, I do not know.

Section 3: Hypothetical scenario and CM question for the proposed tomato

Most of vegetables, especially tomatoes, incur highest usage of synthetic fertilizers and chemical pesticides. Pesticides also contaminate drinking water and food crops. Moreover, some tomato growers use some medicines to accelerate ripening of tomatoes, impart artificial color, and influence the size. This has led to an increase in the food poisoning cases in recent years. It is a serious problem of our country.

If environmentally friendly production systems such as organic farming and GAP were developed not only to resolve the food safety issue but also to preserve the environmental quality by reducing water pollution and promoting soil conservation and soil quality, among others.

In Myanmar, there is a growing concern over the safety of vegetables due to chemical usage, but there is a little understanding of what chemical-free/organic produce would cost. Hence, in this study, I would like to introduce you to two types of eco-friendly farming systems that can be employed in Myanmar. There are two types of environmentally friendly farming systems organic farming system and good agriculture practices (GAP).

The different production and management systems produce different attributes in environmentally friendly tomato. We would like to know your preferences for each attribute. Given below is the detailed information about environmentally friendly tomato along with their attributes. Please, choose your desirable option among the given alternatives of environmentally friendly tomato:

- Tomato A: Organic tomato is certified by MOAG or MOGPA and

- Tomato B: GAP tomato is certified by Ministry of Agriculture, Livestock and Irrigation, Myanmar

Environmentally friendly tomato has the following different attributes:

- Reduction of pesticide: Environmentally friendly tomato can decrease the amount of pesticide used from at least $20 \%$ to $100 \%$ (organic tomato).

- Gaining consumers' trust through labels: There are two types of labels to consider on tomato with or without the certified label because most of tomatoes is sold in the open market are without packaging and labelling.

- Technology for tomato production: The environmentally friendly tomato is grown by greenhouse production system or field production system.

- Freshness level: The freshness level is denoted by days after the harvest ( 0 days, 1 day, and 2 days ago).

- Price: the price of environmentally friendly tomato ranges from 700 to 2,200 MMK per kg depending on the level of environmentally friendly farming.

(1) Choice set 1

(2) Choice set 2

\section{Copyrights}

Copyright for this article is retained by the author(s), with first publication rights granted to the journal.

This is an open-access article distributed under the terms and conditions of the Creative Commons Attribution license (http://creativecommons.org/licenses/by/4.0/). 